EQUILIBRIUM JOURNAL OF

CHEMICAL ENGINEERING

Homepage:https://jurnal.uns.ac.id/equilibrium

\title{
Analisis Morfologi Prekursor NMC811 dari Mix Hydroxide Precipitate (MHP) dengan Presipitan Asam Oksalat
}

\author{
Adhitya Dharmawan, Miftakhul Hakam, Meidiana Arinawati, Cornelius Satria Yudha, dan Agus Purwanto* \\ Program Studi DIII Teknik Kimia, Sekolah Vokasi, Universitas Sebelas Maret, Surakarta, Jawa Tengah, 57126
}

Corresponding Author: aguspurwanto@staff.uns.ac.id

DOI: https://dx.doi.org/10.20961/equilibrium.v5i2.58474

Article History

Received: 15-11-2021, Accepted: 04-12-2021, Published: 13-01-2022

Kata kunci:

EDX, MHP, morfologi,

NMC811,

Prekursor, SEM

Keywords:

EDX, MHP,

Morphology

NMC811,

Precursor, SEM,

\begin{abstract}
ABSTRAK. Morfologi material merupakan salah satu aspek yang berpengaruh pada kualitas material katoda baterai $\mathrm{Li}$-ion atau LIBs, salah satunya material katoda $\mathrm{LiNi}{ }_{0,8} \mathrm{Mn}_{0,1} \mathrm{Co}_{0,1} \mathrm{O}_{2}$ atau NMC811. Semakin baik distribusi ukuran dan butiran partikel, maka semakin baik pula kualitas dari produk akhir NMC811. Penelitian ini bertujuan untuk sintesis dan analisis prekursor NMC811 $\left(\mathrm{Ni}_{0,8} \mathrm{Mn}_{0,1} \mathrm{Co}_{0,1} \mathrm{C}_{2} \mathrm{O}_{4}\right)$ dengan mixed hydroxide precipitate atau MHP sebagai sumber Ni. Pada penelitian ini, prekursor NMC811 oksalat diperoleh dengan melarutkan MHP, $\mathrm{CoSO}_{4}$ dan $\mathrm{MnSO}_{4}$ pada larutan asam asetat. Larutan yang terbentuk dipresipitasi dengan asam oksalat sehingga membentuk endapan prekursor NMC811 oksalat. Instrumen pengujian SEM-EDX digunakan dalam mengevaluasi karakteristik morfologi sampel. Studi komparasi morfologi prekursor NMC811 dengan MHP juga dilakukan. prekursor Berdasarkan analisis komposisional menggunakan EDX, komposisi atom C, O, Mn, Co dan Ni secara berturut-turut 15,21 $\pm 0.55 \%$; 57,64 $\pm 1.37 \%$; $4,47 \pm 0.59 \%$; 4,20 $\pm 0.74 \%$; dan $18,48 \pm 1.71 \%$. Sementara itu, analisis menggunakan SEM menunjukkan bahwa prekursor NMC811 memiliki bentuk dan ukuran partikel yang cenderung seragam dan lebih kompak dibandingkan MHP yang memiliki bentuk dan ukuran yang lebih bervariasi. Sintesis awal NMC811 dengan presipitan asam oksalat dapat meningkatkan keseragaman morfologi yang baik, sehingga nantinya dapat dihasilkan produk akhir NMC811 yang baik pula.
\end{abstract}

\section{PENDAHULUAN}

Seiring dengan perkembangan pasar kendaraan listrik (EV) yang semakin maju, menjadikan adanya pengembangan baterai Lithium Ion semakin besar. Hal ini,untuk menghadapi berbagai tantangan teknis untuk aplikasi EV dalam hal kepadatan energi, kepadatan daya, keandalan dan keamanan. Secara khusus, kemampuan pengisian yang cepat merupakan fitur yang sangat dibutuhkan karena mempersingkat waktu pengisian Baterai Litihium Ion. Sayangnya, teknologi baterai lithium ion saat ini tidak dapat sepenuhnya memenuhi tingkat pengisian yang diinginkan untuk EV. Oleh karena itu, banyak penelitian ditujukan tidak hanya untuk meningkatkan teknologi dalam pengisian baterai, tetapi juga untuk mengurangi biaya produksi LIB secara keseluruhan. Akan tetapi, harga LIB sangat dipengaruhi oleh bahan katoda. Dengan demikian, penghematan biaya penyimpanan energi berbasis LIB dapat ditingkatkan dengan mengurangi biaya bahan katoda tanpa merusak kapasitas dan energi spesifiknya saat ini [1,2]. 
Berbagai upaya telah dilakukan untuk mendapatkan bahan katoda untuk baterai Li-ion. Metode sintesis dikembangkan secara berkala untuk mendapatkan kualitas katoda yang baik dengan kinerja elektrokimia yang sangat baik. Namun, penelitian yang fokus pada bahan baku. Prekursor jenis garam seperti sulfat, klorida, nitrat dan asetat, berulang kali digunakan selama sintesis bahan katoda. Reaksi solid-state biasanya menggunakan prekursor oksida dan hidroksida [3,4]. Saat ini, material katoda bekas dan sisa material katoda yang diperoleh dari industri baterai juga telah digunakan sebagai bahan awal atau bahan baku melalui proses daur ulang. Pengembangan bahan katoda dari produk hulu seperti bijih jarang dilakukan dalam penelitian [5,6].

Dalam penelitian ini, sintesis prekursor bahan katoda kaya nikel jenis lithium nikel kobalt mangan oksida (NMC) dengan campuran endapan hidroksida atau mixed hydroxide precipitate (MHP) sebagai sumber nikel dan uji karakteristik morfologinya dilakukan. Prekursor NMC adalah oksida logam transisi terner (Ni-Co-Mn-O). MHP mengandung nikel dalam jumlah tinggi, namun memiliki sedikit pengotor seperti sulfat, magnesium dan mangan. Meskipun memiliki kualitas yang tinggi, namun memiliki potensi komersialisasi yang tinggi karena nilai ekonomisnya. Kandungan sulfat dapat dengan mudah dihilangkan melalui proses pencucian. Kobalt dan mangan dapat disetel melalui proses hidrometalurgi yang melibatkan pencucian MHP dalam larutan asam. Untuk meningkatkan keramahan lingkungan dari keseluruhan proses, MHP dilindi menggunakan asam organik seperti asam laktat, dan asam asetat. Pada akhirnya, kita dapat berharap bahwa sintesis bubuk prekursor halus NCM yang hijau dan ekonomis dapat dikembangkan untuk keperluan industri.

\section{METODOLOGI}

\subsection{Bahan dan Alat}

Bahan baku yang digunakan pada penelitian ini adalah Mixed hydroxide precipitate (MHP) dengan kandungan Nikel hidroksida dari PT Gebe Industri Nikel. Kobalt sulfat heptahidrat dan mangan sulfat monohidrat dari Rubamin (India) dan Merck (Jerman) secara berturut-turut digunakan sebagai sumber kobalt dan sumber mangan pada produk prekursor NMC Oksalat. Asam asetat dan asam malat (Merck, Jerman) digunakan sebagai pelarut MHP sedangkan asam oksalat digunakan sebagai presipitan. Alat-alat yang digunakan antara lain: pengaduk magnetik dengan pemanas, gelas beaker, saringan dan kertas saring, dan timbangan.

\subsection{Sintesis NMC Oksalat}

Sebanyak $0.4 \mathrm{~mol} \mathrm{Ni(OH})_{2}$ dari MHP dilarutkan dengan $2 \mathrm{M}$ asam asetat sebanyak 0,5 L sambil diaduk dan dipanaskan pada suhu $60^{\circ} \mathrm{C}$ hingga semua endapan MHP terlarut. Kemudian, sebanyak 0.05 mol garam kobalt sulfat dan garam mangan sulfat dilarutkan kedalam larutan. Setelah semua bahan terlarut, $1 \mathrm{M}$ asam oksalat sebanyak 0,5 L direaksikan dengan larutan sambil dipanaskan. Seiring ditambahkan asam oksalat, endapan berwarna hijau kusam terbentuk. Proses pembentukan endapan dilakukan selama 2 jam pada suhu $60^{\circ} \mathrm{C}$. Setelah 2 jam, pengadukan dihentikan dan proses sedimentasi berlangsung. Sedimen didiamkan selama 2 jam. Cairan bening yang bersifat asam dipisahkan kemudian endapan dicuci dengan air hingga pH air cucian mencapai 6-7. Endapan yang telah dicuci disaring kemudian dikeringkan pada oven bersuhu $80{ }^{\circ} \mathrm{C}$ selama 2 jam. Proses diulang dengan mengganti asam asetat dengan asam laktat. Sampel NMC Oksalat yang diproses dengan pelarut MHP asam asetat dan asam laktat diberi nama NMCOA dan NMCOL.

Pengujian karakteristik morfologi dilakukan dengan bantuan pindaian mikroskop elektron atau scanning electron microscopy/SEM (JCM 7000 JEOL, Jepang). Gambar partikel sampel diambil pada perbesaran 10003000x dengan tegangan $15 \mathrm{kV}$. Uji komposisi endapan dilakukan dengan EDAX atau energy dispersive $x$-ray spectroscopy.

\section{HASIL DAN PEMBAHASAN}

\subsection{Kenampakan sampel NMC oksalat}

Proses pembentukan endapan NMC oksalat melalui 3 tahap antara lain: pelarutan MHP dengan asam, penambahan sumber Mn dan Co, dan presipitasi Ni, Mn dan Co secara bersamaan dengan bantuan asam oksalat. Kenampakan endapan MHP dan sampel NMC oksalat (NMCA dan NMCL), dapat dilihat pada Gambar 1. Berdasarkan gambar, dapat diketahui bahwa terdapat perbedaan yang sangat signifikan pada kenampakan sampel MHP dengan prekursor NMC oksalat. Sampel MHP memiliki warna hijau gelap keabuan sedangkan sampel NMCOA dan NMCOL memiliki warna hijau-biru terang. Bentuk bubuk atau powder MHP lebih terlihat kasar dibandingkan NMCOA dan NMCOL yang terlihat halus tanpa adanya perlakuan penumbukan dan pengayaan. 
Hal ini dapat menjadi pertimbangan awal bahwa metode yang diadaptasi pada penelitian ini dapat meningkatkan kualitas kenampakan sampel(7,8).

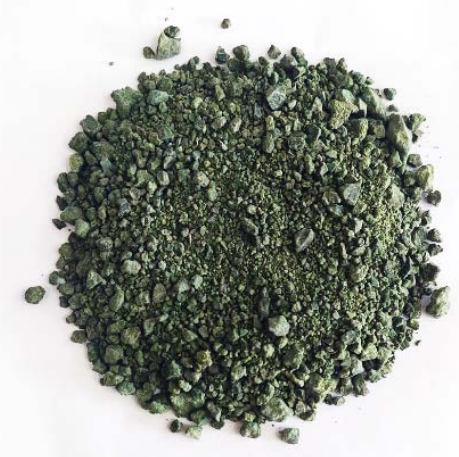

(a) (b)

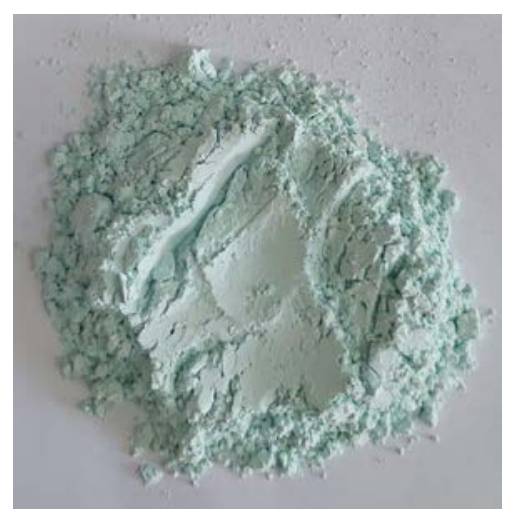

(c)

Gambar 1. Kenampakan sampel endapan (a) MHP, (b) NMCOA, dan (c) NMCOL

\subsection{Uji morfologi sampel NMC oksalat}

Uji morfologi sampel MHP, NMCOA, dan NMCOL dengan bantuan pindaian mikroskop elektron dapat dilihat pada gambar 2. Berdasarkan hasil pindaian, sampel MHP memiliki bentuk partikel yang tidak seragam. Sebagai contoh, pada gambar 2(a-b) terdapat partikel yang berbentuk agglomerat atau seperti batu, namun ada partikel dengan bentuk lembaran-lembaran atau flake. Selain itu, secara kasat mata, rentang ukuran partikel MHP terlihat sangat besar. Sehingga, dapat disimpulkan bahwa ukuran partikel MHP tidak homogen. Pada sampel NMCOA (gambar 2(c-d)) dan NMCOL (gambar 2(e-f)), bentuk dan ukuran partikel cenderung jauh lebih seragam dibandingkan dengan sampel MHP. Sampel NMCOL memiliki bentuk partikel seperti biji kopi dengan permukaan yang sedikit halus, sedangkan pada sampel NMCOA, partikel cenderung membentuk aglomerat semi bulat dengan permukaan yang kasar. Hal ini menunjukkan bahwa terdapat pengaruh yang signifikan pada penggunaan jenis asam pada saat proses pelarutan MHP(9).

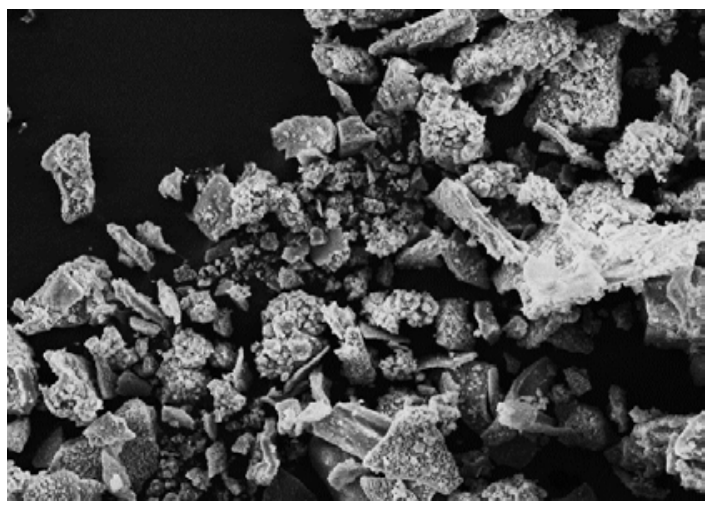

(a)

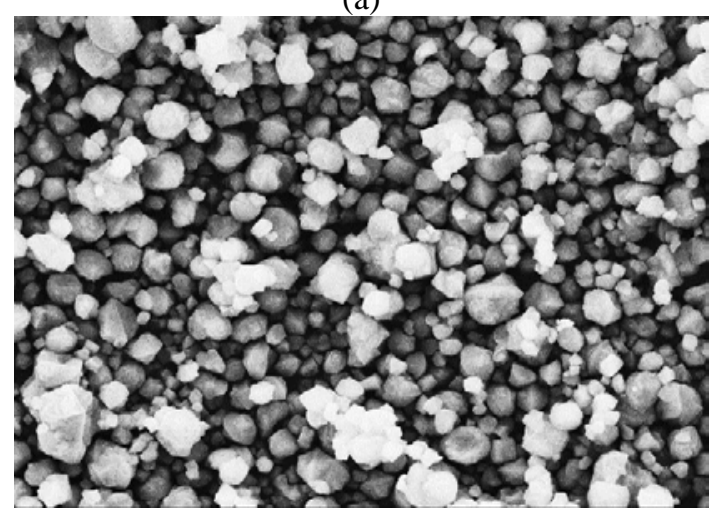

(c)

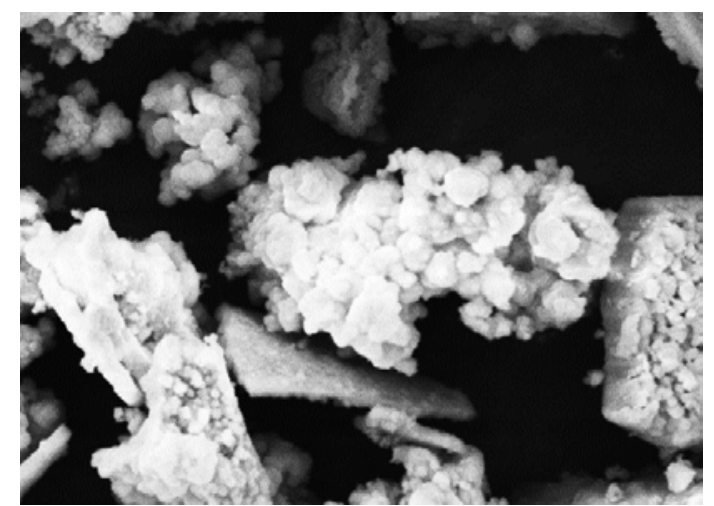

(b)

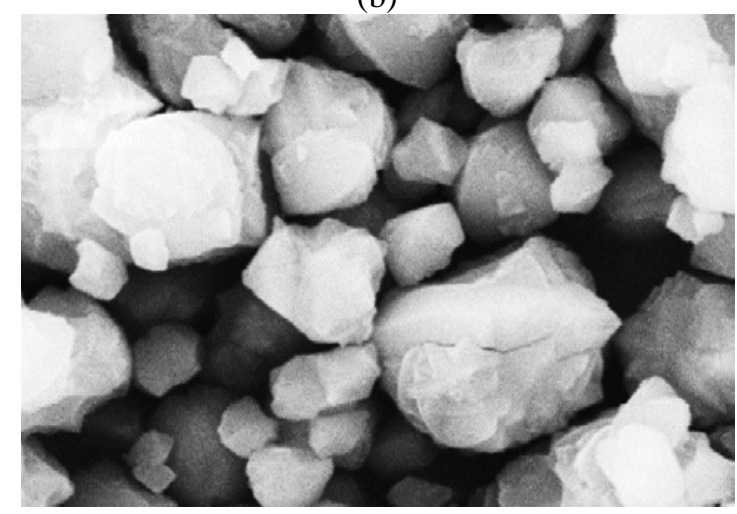

(d) 


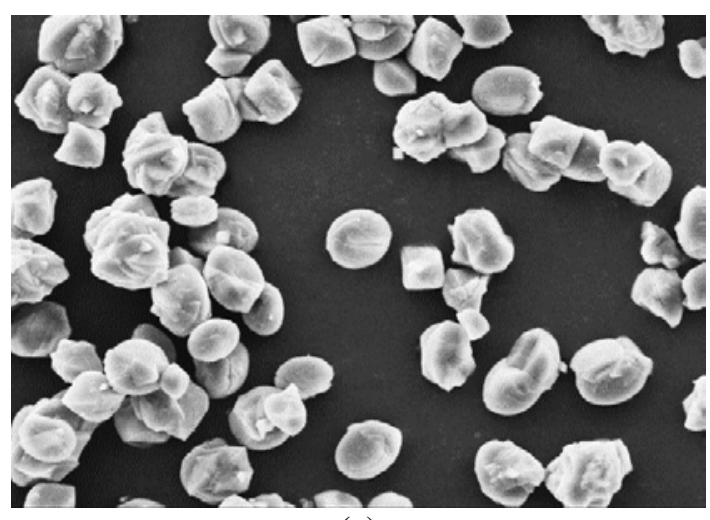

(e)

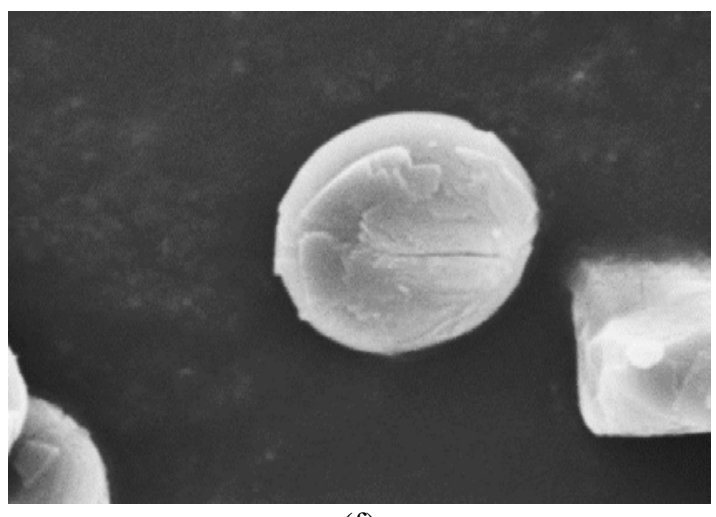

(f)

Gambar 2. Citra SEM sampel pada perbesaran 2500x dan 5000x dari (a,b) MHP, (c,d) NMCOA, dan (e,f) NMCOL

\subsection{Analisis ukuran partikel dan distribusi partikel sampel oksalat}

Analisis terkait ukuran partikel dan distribusi ukuran partikel dilakukan untuk mengevaluasi secara dalam kualitas dan karakteristik sampel NMCOA dan NMCOL. Pengukuran partikel dilakukan dengan bantuan perangkat lunak ImageJ sedangkan pengelompokan data dan analisis secara statistika dilakukan dengan bantuan perangkat lunak Ms. Excel. Gambar 3 menampilkan grafik distribusi partikel sampel NMCOA dan NMCOL. Berdasarkan data modus, dapat disimpulkan bahwa ukuran partikel NMCA lebih kecil dibandingkan dengan ukuran partikel NMCL. Data ukuran rata-rata partikel, D10, D50, D90 dapat dilihat pada tabel 1(10).

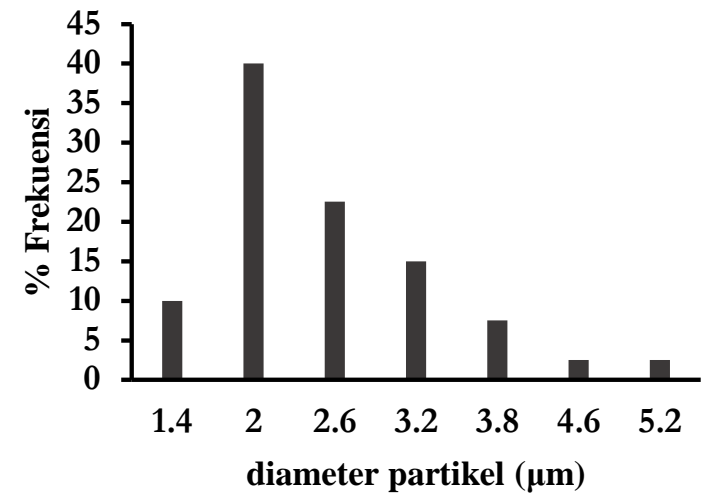

(a)

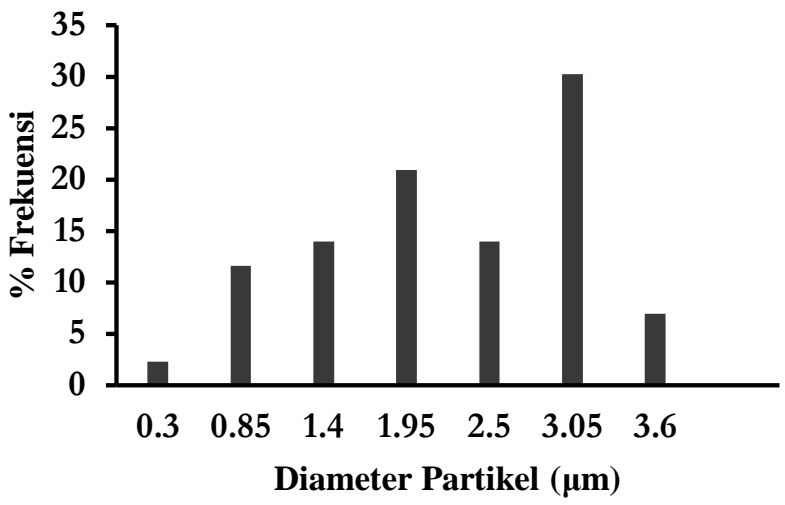

(b)

Gambar 3. Histogram distribusi partikel NMCOA dan NMCOL

Tabel 1. Analisa ukuran partikel NMCOA dan NMCOL

\begin{tabular}{lcc}
\hline \multicolumn{1}{c}{ Parameter } & NMCOA & NMCOL \\
\hline Rata-rata/ $\mu \mathrm{m}$ & 2,303 & 1,972 \\
$\mathrm{D} 10 / \mu \mathrm{m}$ & 1,523 & 0,770 \\
D50 $($ median $) / \mu \mathrm{m}$ & 2,139 & 2,077 \\
D90/ $\mu \mathrm{m}$ & 3,237 & 2,989 \\
Ukuran maksimal/ $\mu \mathrm{m}$ & 5,162 & 3,602 \\
\hline
\end{tabular}

\subsection{Analisis komposisi sampel NMC oksalat}

Analisis komposisi sampel NMC oksalat dilakukan dengan bantuan SEM-EDX atau EDAX. Gambar 4 menunjukan puncak-puncak elemen yang ada pada sampel NMC oksalat. Tabel 2 menampilkan analisis kuantitatif komposisi elemen pada sampel. Berdasarkan hasil dapat dilihat bahwa pada kedua sampel, unsur $\mathrm{C}$ dan $\mathrm{O}$ mendominasi. Hal ini disebabkan karena pada senyawa NMC-oksalat, atom C dan O lebih dominan. Diantara dua sampel, unsur Mg dapat dideteksi pada sampel NMCOL namun tidak pada NMCOA. Walaupun demikian, nilai 
kandungan Mg relatif sangat kecil, selain itu, kandungan Mg pada sampel adalah normal, karena pada MHP terkandung logam Mg dan pada proses presipitasi, Mg ikut terendapkan bersama logam Ni, Mn dan Co. Diantara kandungan logam transisi, nilai Ni paling tinggi, sehingga terdapat kesesuaian dengan target nilai prekursor NMC811, dimana nilai Ni jauh lebih besar dibandingkan nilai Mn dan Co(11,12).

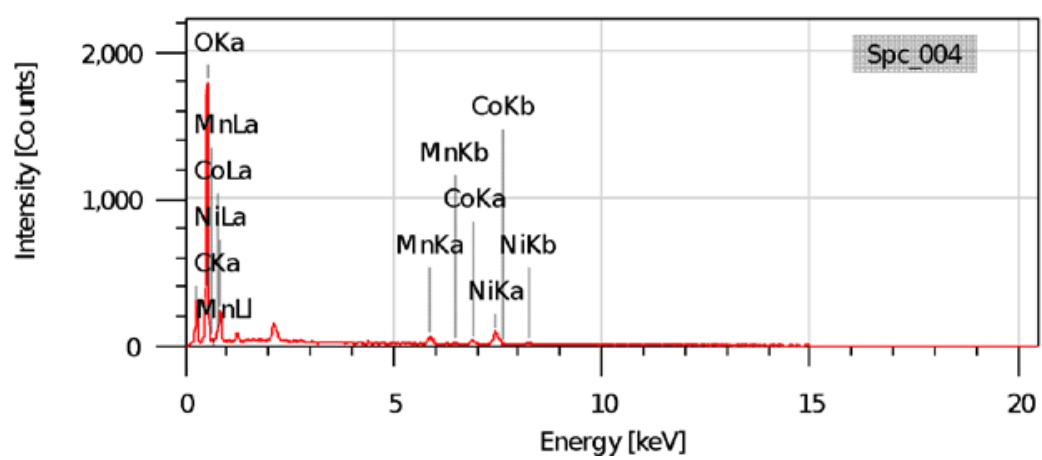

(a)

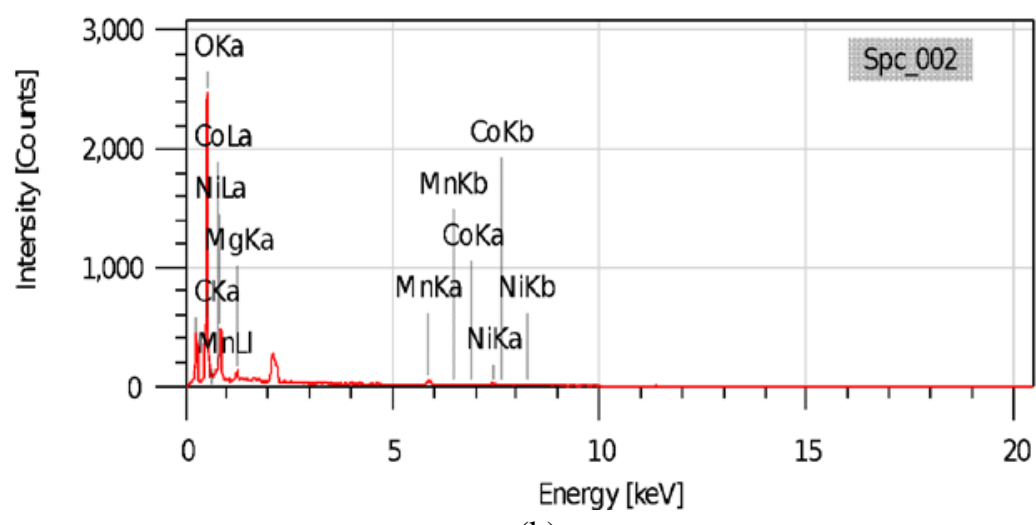

(b)

Gambar 4. Hasil analisis EDAX sampel (a) NMCOA dan (b) NMCOL

Tabel 2. Analisa komposisi unsur pada NMCOA dan NMCOL

\begin{tabular}{lcccc}
\hline Parameter & \multicolumn{2}{c}{ NMCOA } & \multicolumn{2}{c}{ NMCOL } \\
\cline { 2 - 5 } & \%berat & \%atom & \%berat & \%atom \\
\hline $\mathrm{C}$ & $15.21 \pm 0.55$ & $23.73 \pm 0.86$ & $12.41 \pm 0.37$ & $20.54 \pm 0.62$ \\
$\mathrm{O}$ & $57.64 \pm 1.37$ & $67.51 \pm 1.61$ & $54.02 \pm 1.08$ & $67.14 \pm 1.34$ \\
$\mathrm{Mg}$ & - & - & $0.57 \pm 0.23$ & $0.29 \pm 0.09$ \\
$\mathrm{Mn}$ & $4.47 \pm 0.59$ & $1.52 \pm 0.20$ & $8.32 \pm 1.57$ & $3.01 \pm 0.57$ \\
$\mathrm{Co}$ & $4.20 \pm 0.74$ & $1.34 \pm 0.24$ & $1.49 \pm 1.20$ & $1.50 \pm 0.41$ \\
$\mathrm{Ni}$ & $18.48 \pm 1.71$ & $5.90 \pm 0.55$ & $22.18 \pm 5.75$ & $7.51 \pm 1.95$ \\
$\mathrm{~S}$ & - & - & & - \\
\hline
\end{tabular}

\section{KESIMPULAN}

Studi morfologi prekursor NMC811 dalam bentuk nikel mangan kobalt oksalat atau NMC oksalat dari mixed hydroxide precipitate atau MHP telah dilakukan. Pengaruh penggunaan asam asetat dan asam laktat terhadap morfologi partikel telah dipelajari. Bedasakan hasil uji SEM, terdapat perubahan yang signifikan pada bentuk morfologi partikel MHP. Produk yang dilarutkan pada asam asetat atau laktat kemudian dipresipitasi dengan asam oksalat memberikan morfologi partikel yang halus, homogen dan berbentuk semibulat. Ukuran partikel dan distribusi partikel NMC oksalat dipengaruhi oleh jenis asam pelarut. Berdasarkan hasil EDX, nilai C dan O dominan, sedangkan persentasi logam terbesar adalah Ni. Dengan demikian, dapat disimpulkan bahwa studi morfologi ini memberikan bukti nyata bahwa proses pelarutan dan presipitasi MHP layak untuk dikembangkan pada penelitian selanjutnya. 


\section{UCAPAN TERIMA KASIH}

Penulis mengucapkan terimakasih kepada Lembaga Pengelola Dana Pendidikan (LPDP) yang telah mendanai penelitian ini melalui skema RISPRO dengan nomor kontrak 06/PRJ/2019.

\section{DAFTAR PUSTAKA}

[1] Tarascon JM. Key challenges in future Li-battery research. Philos Trans R Soc A Math Phys Eng Sci. 2010;368(1923):3227-41.

[2] Nitta N, Wu F, Lee JT, Yushin G. Li-ion battery materials: Present and future. Mater Today [Internet]. 2015;18(5):252-64. Available from: http://dx.doi.org/10.1016/j.mattod.2014.10.040

[3] Xia S, Zhang Y, Dong P, Zhang Y. Synthesis cathode material LiNi0.8Co0.15Al0.05O2 with two step solidstate method under air stream. Eur Phys Journal-Applied Phys. 2014;65(1):1-6.

[4] Qiu Z, Zhang Y, Wang D, Xia S. A ternary oxide precursor with trigonal structure for synthesis. Solid State Electrochem. 2017;

[5] Meng K, Wang Z, Guo H, Li X, Wang J. A compact process to prepare LiNi0.8Co0.1Mn0.1O2 cathode material from nickel-copper sulfide ore. Hydrometallurgy. 2017;174(May):1-9.

[6] Purwanto A, Yudha CS, Ubaidillah U, Widiyandari H, Ogi T, Haerudin H. NCA cathode material: Synthesis methods and performance enhancement efforts. Mater Res Express. 2018;5(12).

[7] Małecka B, Małecki A, Drozdz-Cieśla E, Tortet L, Llewellyn P, Rouquerol F. Some aspects of thermal decomposition of NiC2O4·2H2O. Thermochim Acta. 2007;466(1-2):57-62.

[8] Qiu Z, Zhang Y, Dong P, Xia S, Yao Y. A facile method for synthesis of LiNi0.8Co0.15Al0.05O2 cathode material. Solid State Ionics. 2017;307(December 2016):73-8.

[9] Nurcahyani C, Anjani AE, Purwanto A, Yudha CS, Hasanah LM, Dyartanti ER, et al. Flame-assisted spray pyrolysis of lithium nickel cobalt aluminum oxide leaching stream. AIP Conf Proc. 2020;2219(May).

[10] Hatchard TD, Dahn JR, Soc JE, A-a P, Hatchard TD, Dahn JR. In Situ XRD and Electrochemical Study of the Reaction of Lithium with Amorphous Silicon service In Situ XRD and Electrochemical Study of the Reaction of Lithium with Amorphous Silicon. 2004;151(6).

[11] Li J, Shunmugasundaram R, Doig R, Dahn JR. In Situ X-ray Diffraction Study of Layered Li-Ni-Mn-Co Oxides: Effect of Particle Size and Structural Stability of Core-Shell Materials. Chem Mater. 2016;28(1):162-71.

[12] Zhu J, Zheng J, Cao G, Li Y, Zhou Y, Deng S, et al. Flux-free synthesis of single-crystal LiNi0.8Co0.1Mn0.1O2 boosts its electrochemical performance in lithium batteries. J Power Sources. 2020;464(April):228207. 